\title{
Stabilizing Tin Anodes in Sodium-Ion Batteries by Alloying with Silicon
}

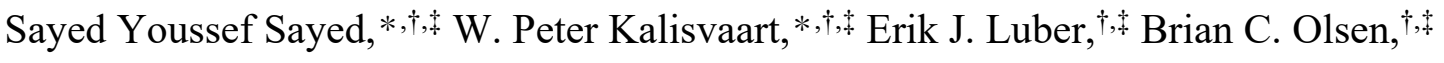 \\ and Jillian M. Buriak*,†,末 \\ †Department of Chemistry, University of Alberta, 11227-Saskatchewan Drive, \\ Edmonton, AB T6G 2G2, Canada \\ \$National Research Council Canada, Nanotechnology Research Centre, Edmonton, AB \\ T6G 2M9, Canada
}




\section{ABSTRACT}

Group(IV) of the periodic table is a promising column with respect to high capacity anode materials for sodium-ion batteries (SIBs). Unlike carbon that relies on interlayer defects, pores, and intercalation to store sodium, its heavier cousins, silicon, germanium, and tin, form binary alloys with sodium. Alloying does lead to the formation of high capacity compounds but they are, however, susceptible to large volumetric changes upon expansion that results in pulverization of the electrodes and poor cycling stability. Silicon and tin are particularly intriguing due to their high theoretical reversible capacities of 954 $\mathrm{mAh} / \mathrm{g}(\mathrm{NaSi})$ and $847 \mathrm{mAh} / \mathrm{g}\left(\mathrm{Na}_{15} \mathrm{Sn}_{4}\right)$, respectively, but suffer from poor practical capacity and very short lifetimes, respectively. In order to buffer the detrimental effects of volume expansion and contraction, nanoscale multilayer anodes comprising silicon and tin films were prepared and compared with uniform films composed of atomically mixed silicon and tin, as well as elemental silicon and tin films. The results reveal that the high capacity fade for elemental $\mathrm{Sn}$ is associated with detrimental anodic (desodiation) reactions at a high cutoff voltage with a threshold defined as $\sim 0.8 \mathrm{~V}_{\mathrm{Na}}$. Binary mixtures of Si and Sn were tested in a number of different architectures, including multilayer films and co-sputtered films with varying volume ratios of both elements. All mixed films showed improved capacity retention compared to the performance of anodes comprising only elemental $\mathrm{Sn}$. A multilayer structure composed of $3 \mathrm{~nm}$-thick silicon and tin layers showed the highest Coulombic efficiency and retained $97 \%$ of its initial capacity after 100 cycles, which is vastly improved compared to $7 \%$ retention observed for the elemental Sn film. The role of the Si interlayers appears to be one of acting as a buffer during cycling to help preserve Sn particles within the thin Sn interlayers. The alloying element, $\mathrm{Si}$, plays two roles - it stabilizes grain growth/pulverization and also alters the surface chemistry of the anodes, thus affecting the formation of solid electrolyte interphase (SEI).

\section{Keywords:}

Sn-based anodes; binary mixtures; sodium-ion batteries; multilayers, silicon 


\section{Graphical Abstract}

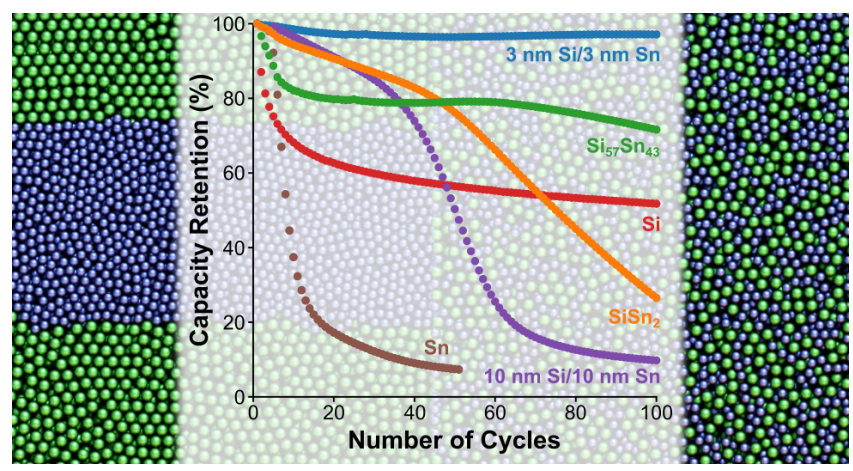




\section{INTRODUCTION}

The development of efficient and cost-effective electrical energy storage systems is urgently needed not only to meet the growing demands for portable electronics and electric vehicles but also to complement the integration of renewable energy into smart grids. ${ }^{1,2}$ Rechargeable batteries, and lithium-ion batteries (LIBs) in particular, are among the most versatile, and already play a key role with respect to enabling the transition from fossil fuels to a clean and renewable mix of energy sources. ${ }^{3,4}$ However, because of the growing demands for lithium-based rechargeable batteries and geographical constraints on lithium resources, questions have been raised regarding sustainability amid expansion to grid-scale. ${ }^{5,6}$ Consequently, there has been increasing interest in research focused on developing "beyond lithium-ion" batteries. ${ }^{7-9}$

Sodium-ion batteries (SIBs) are not hampered by limits on quantity due to the high abundance of sodium in the earth's crust. Moving from lithium to sodium batteries, however, is expected to be associated with a high energy density penalty of ca. $15 \%$ as a result of the three times higher molar mass of sodium and its $0.3 \mathrm{~V}$ lower electropositivity compared to lithium. ${ }^{2,10,11}$ Efficient cathode and anode materials for SIBs need to be developed and optimized specifically for this ion. Cathode materials being studied for SIBs include layered metal oxides, hexacyanoferrate, and polyanionic frameworks. ${ }^{10,12,13}$ Graphite has been used as the native anode material for LIBs since 1991, but $\mathrm{Na}$ intercalation into graphite and the formation of $\mathrm{NaC}_{6}$ is thermodynamically unfavorable. ${ }^{14}$ On the other hand, glucose-derived hard carbon, a non-graphitic carbon, was found to store $\mathrm{Na}$ ions in-between the disordered graphene sheets and associated pores, a storage mechanism described as the "house-of-cards" model by Dahn and coworkers in the early 2000s. ${ }^{15-17}$ Hard carbon has been considered the "first generation" anode for SIBs, but nevertheless it still shows a limited reversible capacity of ca. 300-380 $\mathrm{mAh} / \mathrm{g} .{ }^{18,19}$ Thus, the development of high capacity alternative anode materials for SIBs is needed if they are to meet the demands of future energy storage systems.

Other Group IV elements beyond carbon have been examined as high capacity anode materials that store $\mathrm{Na}$ not via intercalation or storage in pores, but through the formation of binary alloys. Binary alloys of $\mathrm{Si}, \mathrm{Ge}, \mathrm{Sn}$, and $\mathrm{Pb}$ have theoretical capacities of 954 
$\mathrm{mAh} / \mathrm{g}$ for NaSi, $369 \mathrm{mAh} / \mathrm{g}$ for $\mathrm{NaGe}, 847 \mathrm{mAh} / \mathrm{g}$ for $\mathrm{Na}_{15} \mathrm{Sn}_{4}$ and $485 \mathrm{mAh} / \mathrm{g}$ for $\mathrm{Na}_{15} \mathrm{~Pb}_{4}$, respectively. ${ }^{20,21} \mathrm{Si}$ and $\mathrm{Sn}$ may be the most preferable of this series of elements due to their comparatively higher natural abundance compared to Ge, lower toxicity compared to $\mathrm{Pb}$, and their higher theoretical capacities. ${ }^{22}$ The insertion of $\mathrm{Na}$ into Si has been found to be highly dependent on its crystallinity owing to the high activation energy of the diffusion of $\mathrm{Na}$ ions into c-Si, while the large interstitial sites in a-Si improve $\mathrm{Na}^{+}$ transport and lower the diffusion barrier. ${ }^{23,24}$ Legrain et al. reported that the insertion of $\mathrm{Na}$ into a-Si is thermodynamically favored and that the formation energy of a sodium interstitial in a-Si is $1.42 \mathrm{eV}$ lower than in $\mathrm{c}-\mathrm{Si}^{24}$ Thus, a-Si was found to theoretically allow for the absorption of $0.76 \mathrm{Na}$ atoms per $\mathrm{Si}$, corresponding to a specific capacity of $725 \mathrm{mAh} / \mathrm{g}{ }^{25}$ However, this theoretical capacity has never been reached experimentally. Reported specific capacities are usually around $250 \mathrm{mAh} / \mathrm{g}$, even for very small $(\sim 10 \mathrm{~nm}$ diameter) nanoparticles, ${ }^{26}$ which points to the slow diffusion of $\mathrm{Na}$ in $\mathrm{Si}^{27,28}$ Thin films of silicon with few-layer graphene at the interface with the current collector have been shown to increase reversible capacity by almost a factor of 2, suggesting that slow solidstate diffusion is not solely responsible for the low practical capacities. ${ }^{27}$

Although Sn promises the second highest specific capacity among Group IV elements, it suffers from large volumetric expansion ( 420\%) that leads to severe pulverization, which further disrupts the electrode integrity and results in rapid deterioration in cycling capacity. ${ }^{29,30}$ Nanostructuring the Sn to alleviate these problems related to volume expansion effect has been undertaken, but at the expense of the associated Coulombic efficiency. ${ }^{31-33}$ Alloying Sn with active elements has also led to significant improvement in the cycling of Sn-based anodes in LIBs and SIBs. ${ }^{34-36}$ From the known crystallographic parameters of $\mathrm{NaSi}^{37}$ the volume expansion associated with the full sodiation of Si is only $114 \%$ and, therefore, Si is a good binary alloy candidate as it will greatly reduce the total material expansion while retaining the high specific capacity. The mutual equilibrium solid solubility among the Group IV elements is generally quite low and only $\mathrm{Si}$ and Ge are miscible over the full compositional range. However, metastable solid solubility extensions, even in crystalline phases as well as amorphous ones, have been found for Sn-Ge, and they showed improved capacity retention as SIB anodes. ${ }^{29,38}$ Due to its chemical similarity to Ge, Si may form analogous 
metastable phases with Sn. Here we investigate the performance and electrochemical properties of silicon-tin mixtures of different architectures as anodes for sodium-ion batteries. Earlier work in our group had shown that nanoscale multilayers comprising silicon and carbon presented advantages over atomically mixed films due to buffering of the volume expansion upon cycling in lithium-ion batteries. ${ }^{39}$ To better understand the influence and role of nanostructuring on silicon and tin mixtures, these elements were incorporated into multilayers and atomically mixed films and screened as candidates for SIB electrodes. Multilayers of silicon and tin showed dramatically better performance as anodes in SIBs, a direct result of the nanostructuring that stabilizes the material to pulverization while modifying the surface chemistry of the anode.

\section{EXPERIMENTAL METHODS}

Materials and equipment: Fluoroethylene carbonate (FEC) (99\%), metallic $\mathrm{Na}(99.9 \%)$, and $1.0 \mathrm{M}$ sodium perchlorate $\left(\mathrm{NaClO}_{4}\right)$ solutions in ethylene carbonate and diethyl carbonate (EC/DEC), 1:1 v/v\% battery-grade, were purchased from Sigma-Aldrich. Copper foil was purchased from McMaster Carr. The stainless-steel spacers, springs, and caps were all purchased from MTI Corporation. Polypropylene-polyethylenepolypropylene separators, with a porosity of 39\% (Celgard $\left.{ }^{\mathrm{TM}} 2325\right)$, were used. Sputtering targets were purchased from Plasmaterials, Inc. ATC Orion 8 instrument, AJA International Inc., was used for sputtering performed in argon ( $5 \mathrm{~N}$ purity) supplied by Praxair Canada Inc. Sample weights were determined after deposition using a Mettler Toledo XP6U balance that has a repeatability of $0.4 \mu \mathrm{g}$. Electrochemical measurements were performed using an Arbin BT2000 battery testing system.

Electrode preparation and battery assembly. Copper foils of $15 \mathrm{~mm}$ diameter were used as current collectors and substrates for sputtering and were cleaned by sequential sonication for $10 \mathrm{~min}$ in each of acetone and isopropanol. Sputtered films of elemental Si or Sn, co-sputtered, or multilayer films were deposited for a total thickness of ca. $100 \mathrm{~nm}$ on the current collectors, Figure 1. Gravimetric capacities were calculated based on the average weight of the $100 \mathrm{~nm}$ films. Silicon (n-type) was deposited with DC magnetron sputtering, while tin deposition was performed by radio-frequency magnetron sputtering. Sputtering was carried out with continuous substrate rotation under argon gas 
at a pressure of 5 mTorr. For multilayer deposition and the co-sputtered $\mathrm{Si}_{57} \mathrm{Sn}_{43}$ samples, the sputtering rate was $1.4 \mathrm{~nm} / \mathrm{min}$ for both silicon and tin. For the co-sputtered $\mathrm{SiSn}_{2}$ samples, Si and Sn were co-deposited at rates of $0.774 \mathrm{~nm} / \mathrm{min}$ and $2.08 \mathrm{~nm} / \mathrm{min}$, respectively. Coin cells (2032) were assembled using $\mathrm{Na}$ foil counter electrodes, two layers of polypropylene-polyethylene-polypropylene separators, stainless steel spacers, springs, and caps. The electrolyte was $1.0 \mathrm{M} \mathrm{NaClO}_{4}$ in $\mathrm{EC} / \mathrm{DEC}$ with a volume ratio of 1:1 mixed with FEC (10\% by weight). The used volume of the electrolyte inside the battery was $45 \mu \mathrm{L}$. The battery assembly was performed in an argon glovebox with oxygen and moisture levels below $0.2 \mathrm{ppm}$.

Electrochemical testing. Galvanostatic charge-discharge experiments were performed in the voltage range of $1 \mathrm{mV}_{\mathrm{Na}}-2 \mathrm{~V}_{\mathrm{Na}}$. The batteries were further cycled at a constant current (CC) at a rate of $200 \mathrm{~mA} / \mathrm{g}_{\text {electrode. }}$ Constant voltage (CV) steps, with a current limit of $20 \mathrm{~mA} / \mathrm{g}$, were performed at a sodiation cutoff voltage ( $\left.1 \mathrm{mV}_{\mathrm{Na}}\right)$, following the constant current steps. All coin cells were cycled in a temperaturecontrolled chamber maintained at $25.0 \pm 0.1^{\circ} \mathrm{C}$. Cycled batteries were disassembled in an argon glovebox and soaked for two minutes in diethyl carbonate to remove residual electrolyte before further characterization.

Characterization. Scanning electron microscopy (SEM) analysis was carried out with a Zeiss Sigma Field Emission SEM at an accelerating voltage of $5 \mathrm{kV}$. X-ray diffraction (XRD) analysis was performed in glancing angle mode (incident angle of $3^{\circ}$ ) on a Rigaku IV diffractometer with $\mathrm{Cu} \mathrm{K} \alpha$ radiation $(\lambda=1.5406 \AA)$. 


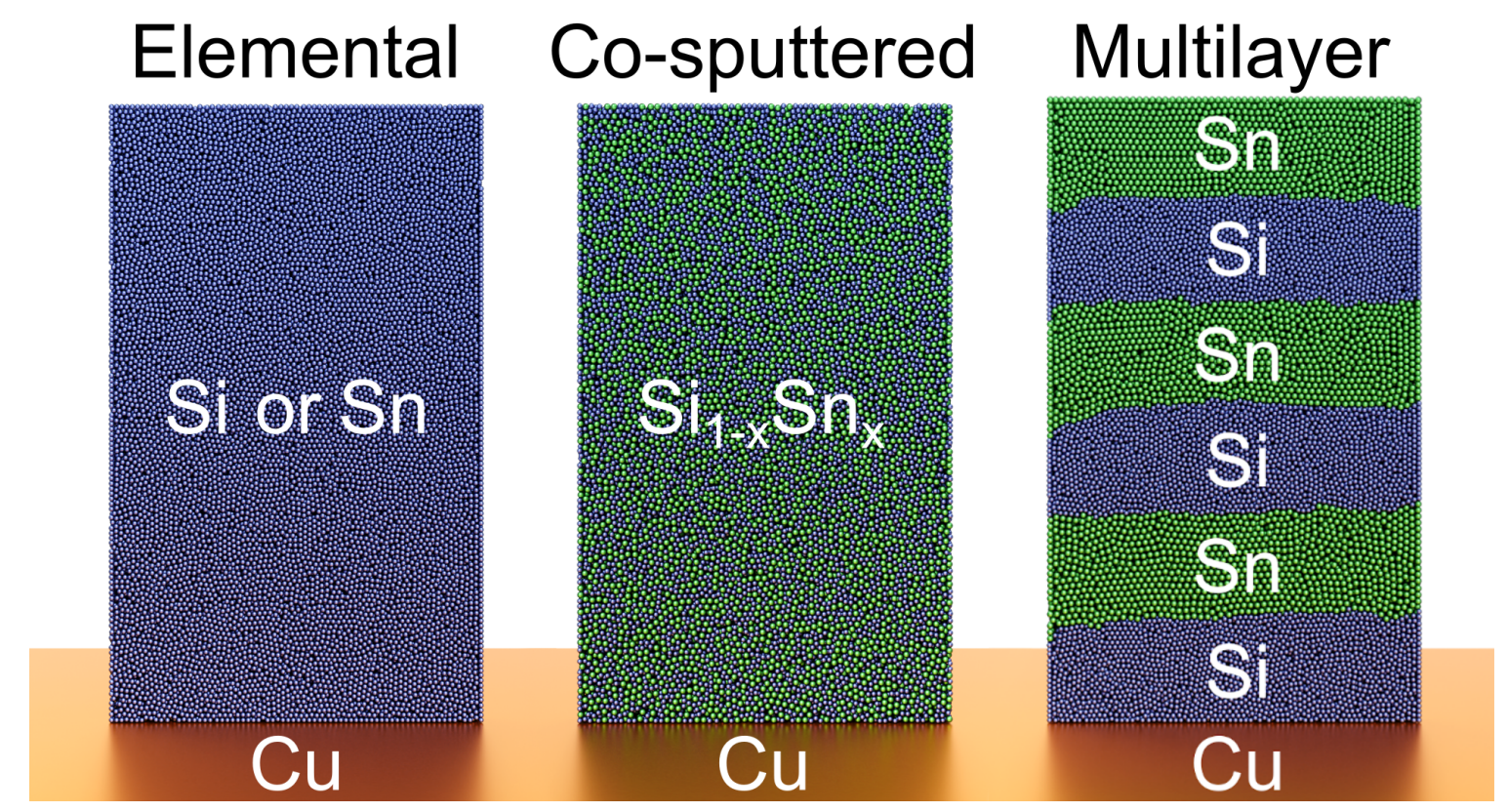

Figure 1. Schematic illustrating the different electrode compositions tested in this work - elemental Si and Sn, co-sputtered, and multilayer films. The nominal film thicknesses range from $50 \mathrm{~nm}$ for elemental Si or Sn films to $100 \mathrm{~nm}$ for the cosputtered and multilayer films, except for the multilayer films comprising $3 \mathrm{~nm} \mathrm{Si} / 3$ $\mathrm{nm} \mathrm{Sn}$ layers where the final total thickness was $102 \mathrm{~nm}$.

\section{RESULTS AND DISCUSSION}

\section{Elemental Sn anodes}

In order to investigate the performance of binary mixtures of $\mathrm{Si}$ and $\mathrm{Sn}$ as anode materials for SIBs, we prepared three different architectures, elemental Si or Sn, cosputtered Si and Sn, and alternating multilayers of both elements (Figure 1). Figure 2a shows the (de)sodiation profiles, voltage $v s$ capacity, for a SIB half-cell with a $50 \mathrm{~nm}$ thick anode film of Sn at different cycles; electrochemical cycling was carried out at a constant current (CC) of $200 \mathrm{~mA} / \mathrm{g}$ between $1 \mathrm{mV}_{\mathrm{Na}}$ and $1 \mathrm{~V}_{\mathrm{Na}}$ for sodiation and desodiation, respectively. In addition, a constant-voltage (CV) step at $1 \mathrm{mV}_{\mathrm{Na}}$ (until the current decreases to $20 \mathrm{~mA} / \mathrm{g}$ ) was applied after the $\mathrm{CC}$ steps for sodiation to ensure that the equilibrium terminal intermetallic is formed. As shown in Figure 2a, a maximum reversible capacity of $830 \mathrm{mAh} / \mathrm{g}$, close to the theoretical capacity $(847 \mathrm{mAh} / \mathrm{g}$ ) for full sodiation of elemental $\mathrm{Sn}$ and the formation of $\mathrm{Na}_{15} \mathrm{Sn}_{4},{ }^{40}$ was observed at the second cycle. Moreover, the corresponding desodiation profile has four flat desodiation plateaus at ca. $0.17,0.26,0.55$ and $0.66 \mathrm{~V}_{\mathrm{Na}}$, which are more clearly revealed as defined peaks in 
the corresponding differential capacity plot (dQ/dV vs voltage) in Figure $2 \mathrm{~b}$. The observed four desodiation peaks indicate a dealloying mechanism that includes four different $\mathrm{Na}$-Sn phases, which is in agreement with the initial density functional theory (DFT) calculations by Chevrier and Ceder. ${ }^{41}$ Through detailed coulometry and in situ XRD analysis, Ellis et al. proposed also a two-phase transition mechanism defining the four Na-Sn phases according to the inset reactions shown in Figure $2 b,{ }^{42}$ in which crystalline c-NaSn 3 and c- $\mathrm{Na}_{15} \mathrm{Sn}_{4}$ are the initial and fully sodiated $\mathrm{Sn}$ phases, respectively. The formation of $\mathrm{Na}_{9} \mathrm{Sn}_{4}$ at room temperature, however, is still controversial. ${ }^{40}$ Baggetto et al. suggested instead that the formation of a metastable phase $\left(\mathrm{Na}_{7} \mathrm{Sn}_{3}\right)$ occurs at ca. $0.06 \mathrm{~V}_{\mathrm{Na}}$ and $0.20 \mathrm{~V}_{\mathrm{Na}}$ during sodiation and desodiation, respectively. ${ }^{43}$ 

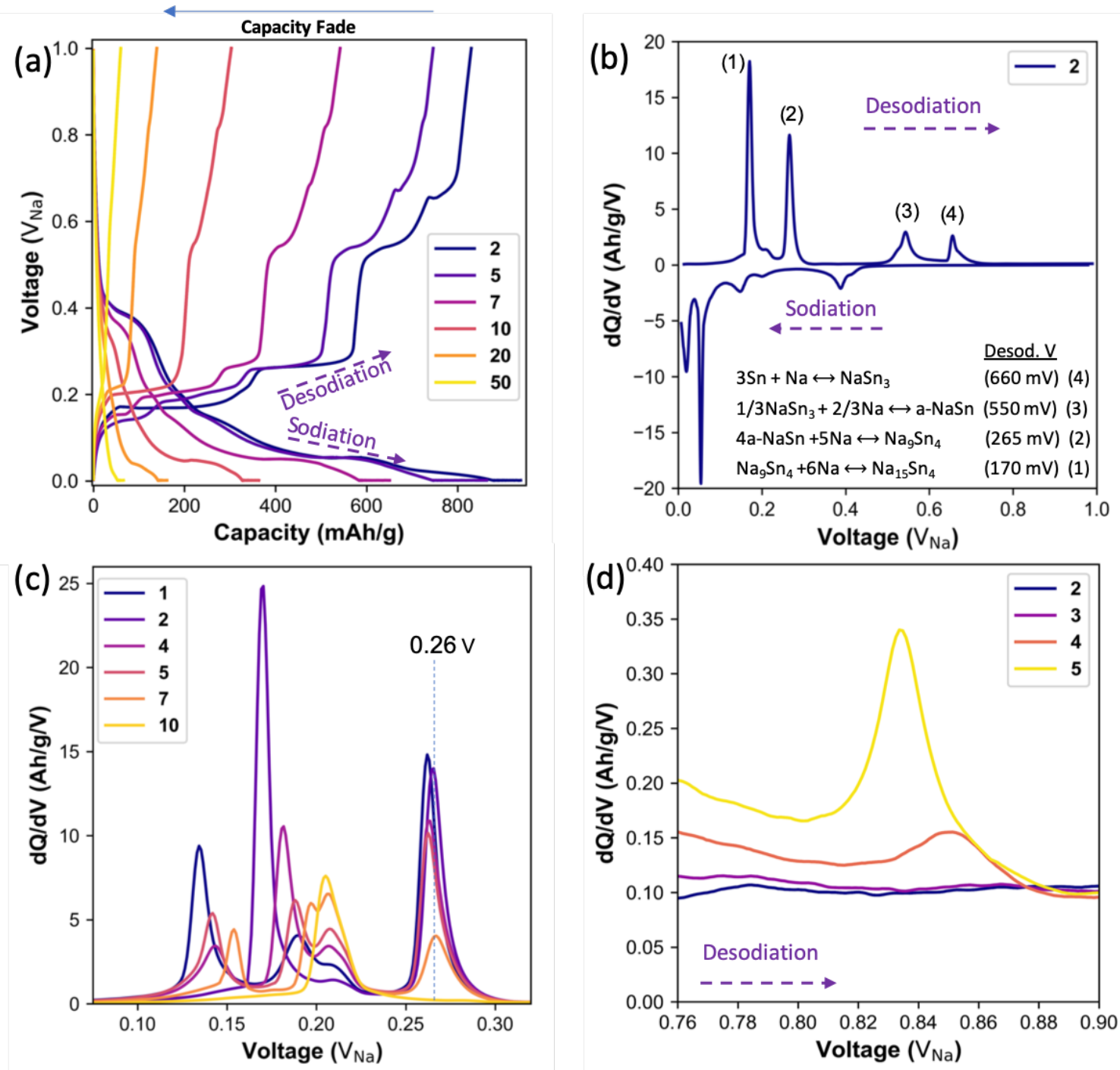

Figure 2. (a) Voltage vs capacity (b-d) and differential capacity vs voltage for a 50$\mathrm{nm}$ thick Sn film cycled using a CCCV protocol during sodation with $1 \mathrm{mV}$ cutoff voltage for sodiation and a $\mathrm{CC}$ protocol with a $1 \mathrm{~V}_{\mathrm{Na}}$ cutoff voltage during desodiation. The plateaus at the end of sodiation at $1 \mathrm{mV} \mathrm{Na}$ in panel (a) represent the contributed capacity from the constant voltage steps. Cycle number is indicated in each corresponding figure legend. The numbers defining the desodiation peaks in (b) refer to the inset reactions proposed by Ellis et al. ${ }^{40}$

Figure $2 \mathrm{a}$ also reveals the trend in the capacity decay upon cycling. For instance, the reversible capacity decays from $830 \mathrm{mAh} / \mathrm{g}$ at the $2^{\text {nd }}$ cycle to $655,360,144$, and 61 $\mathrm{mAh} / \mathrm{g}$ at the $7^{\text {th }}, 10^{\text {th }}, 20^{\text {th }}$, and $50^{\text {th }}$ cycles, respectively. The capacity decays dramatically during the first 10 cycles, coupled with the desodiation profiles showing the evolution of new sloping regions, especially in the voltage regions before $0.26 \mathrm{~V}_{\mathrm{Na}}$ and beyond $0.8 \mathrm{~V}_{\mathrm{Na}}$. For instance, the desodiation profile in Figure 2a shows that during the 
fifth cycle there are three sloping regions at $0.14,0.19$ and $0.21 \mathrm{~V}_{\mathrm{Na}}$ prior to the desodiation plateau at $0.26 \mathrm{~V}_{\mathrm{Na}}$. Moreover, after 10 cycles, the desodiation plateau at 0.26 $\mathrm{V}_{\mathrm{Na}}$ as well as all the preceding plateaus disappeared, with the exception of the one a 0.21 $\mathrm{V}_{\mathrm{Na}}$ (Figure 2a) indicating that dealloying proceeds through a different reaction pathway at this stage of cycling. Interestingly, the differential capacity desodiation profiles shown in Figure 2c reveal the evolution of 8 different peaks at different desodiation voltages in the range of $0.12 \mathrm{~V}_{\mathrm{Na}}$ and $0.23 \mathrm{~V}_{\mathrm{Na}}$ during the initial 7 cycles. The corresponding desodiation peaks at $0.26 \mathrm{~V}_{\mathrm{Na}}$ did not show any noticeable shift during the first 7 cycles, thus excluding any effect for a possible inherent film resistance or polarization during cycling. As such, the desodiation peaks in the voltage range of $0.12 \mathrm{~V}_{\mathrm{Na}}$ and $0.23 \mathrm{~V}_{\mathrm{Na}}$ suggest that the severely deteriorated performance and poor cycle life of Sn anodes are associated with desodiation reactions, and include several Na-Sn phases with close compositions, of which some are possibly amorphous in nature as inferred by the sloping nature of the characteristic desodiation (voltage-capacity) profiles. Finally, Figure $2 \mathrm{~d}$ shows a noticeable peak at ca. $0.83 \mathrm{~V}_{\mathrm{Na}}$ in the desodiation scan, which starts to appear after the $4^{\text {th }}$ cycle. XRD analysis of an Sn electrode after desodiation up to $0.8 \mathrm{~V}_{\mathrm{Na}}$ did not show any diffraction patterns other than those for polycrystalline Sn, indicating full desodiation and the absence of any Na-Sn phases (Figure S1). Moreover, Sn is known to catalyze the decomposition of carbonate-based electrolytes during the discharge (lithiation or sodiation reactions) processes in $\mathrm{Li}$ - and $\mathrm{Na}$-ion batteries through a reductive mechanism. ${ }^{44,45}$ Thus, the anodic/charge peak at $0.83 \mathrm{~V}_{\mathrm{Na}}$, Figure $2 \mathrm{~d}$, might indicate surface anodic reactions to the metallic Sn, vide infra. 

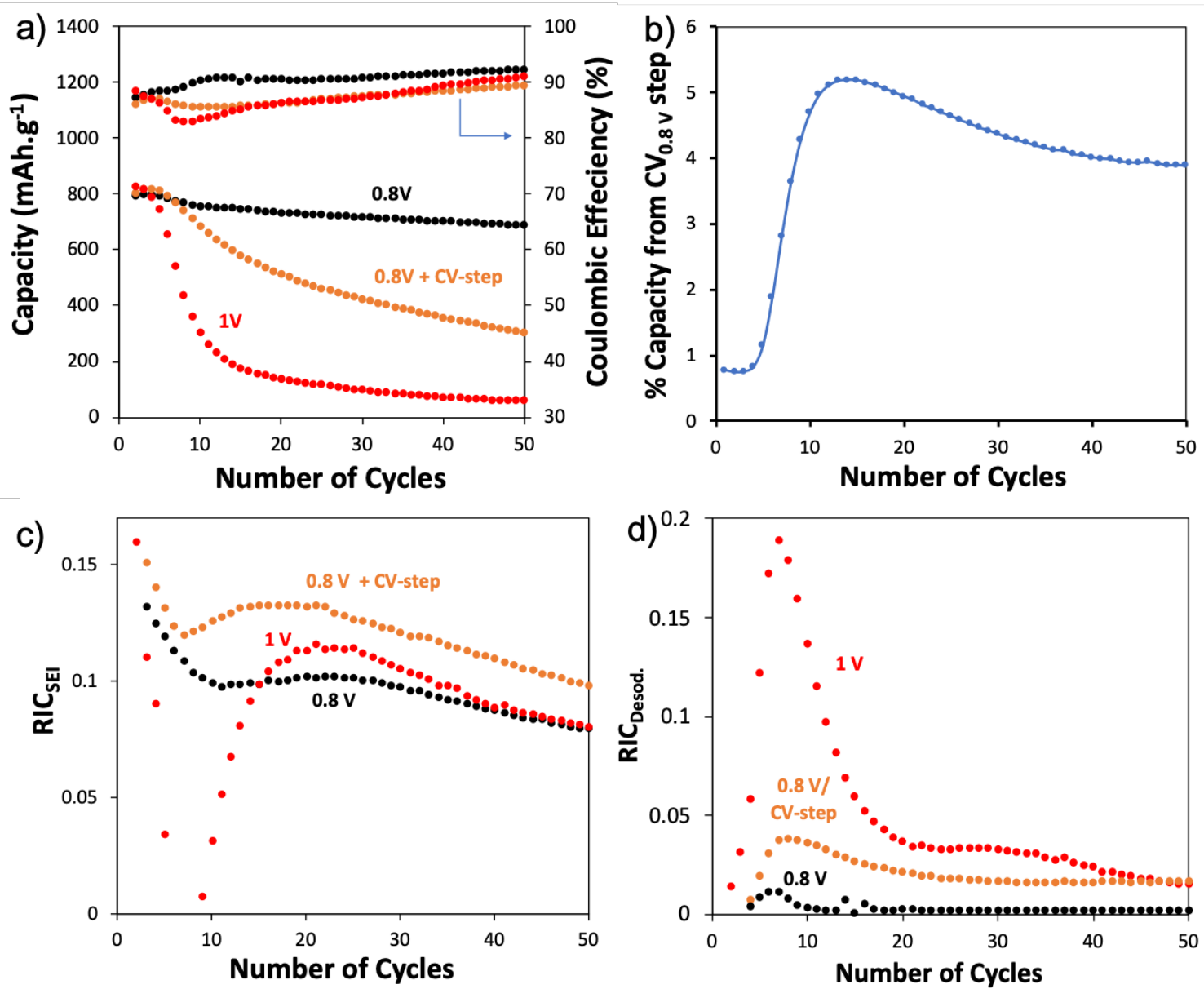

Figure 3. (a) Capacity and Coulombic efficiency vs number of cycles for Sn-based SIBs run at desodiation cutoff voltages of $0.8 \mathrm{~V}_{\mathrm{Na}}$, with and without applying a $\mathrm{CV}$ step and $1 \mathrm{~V}_{\mathrm{Na}}$. (b) Percentage capacity contributed from constant voltage steps for desodiation at $0.8 \mathrm{~V}_{\mathrm{Na}} v s$ number of cycles. (c) Relative irreversible capacity for the formation of SEI (RICSEI) and (d) relative irreversible desodiation capacity ( RIC $_{\text {Desod }}$ vs number of cycles.

Huang et al. recently reported a detailed surface analysis for Sn anodes cycled up to 1 $\mathrm{V}_{\mathrm{Na}}$ in a carbonate-based electrolyte and showed evidence for the electrolyte decomposition through the observation of a thick (ca. $30 \mathrm{~nm}$ ) passivating layer, a solid electrolyte interphase (SEI) composed of inorganic species as well as " $\mathrm{SnO}_{\mathrm{x}}$ or organosiloxane-like species"' that lead to irreversible capacity loss and low Coulombic efficiency (CE) during cycling. ${ }^{32}$ Moreover, the formation of $\mathrm{Sn}^{4+} / \mathrm{Sn}^{2+}$ species on the surface of $\mathrm{Sn}$ anodes cycled up to 1.6 or $2 \mathrm{~V}_{\mathrm{Na}}$ was also revealed by X-ray photoelectron spectroscopy (XPS). ${ }^{43}$ As shown in Figure S2, the differential capacity plots for an Sn electrode charged up to $2 \mathrm{~V}_{\mathrm{Na}}$ showed only one anodic peak at $0.84 \mathrm{~V}_{\mathrm{Na}}$, in the range 
between $0.80 \mathrm{~V}_{\mathrm{Na}}$ and $2.0 \mathrm{~V}_{\mathrm{Na}}$ during the desodiation scans, which might be attributed to surface oxidation of Sn. Thus, in order to investigate the effect of the charging peak at $0.83 \mathrm{~V}_{\mathrm{Na}}$ on the performance of the $\mathrm{Sn}$ anode, we limited the desodiation cutoff voltage to $0.8 \mathrm{~V}_{\mathrm{Na}}$. Interestingly, the capacity loss after 50 cycles is only $13 \%$ compared to $93 \%$ for $1 \mathrm{~V}_{\mathrm{Na}}$ cutoff voltage (Figure 3a). Moreover, the CE showed a clear improvement during cycling compared to a cutoff voltage of $1 \mathrm{~V}_{\mathrm{Na}}$ (Figure $3 \mathrm{a}$ ) and thus indicates less irreversible capacity loss during cycling.

As mentioned above, charging the $\mathrm{Sn}$ half-cell up to a cutoff voltage of $0.8 \mathrm{~V} \mathrm{Na}$ showed a significant improvement in the overall cell performance. The anodic peak at $0.83 \mathrm{~V}_{\mathrm{Na}}$ (Figure $2 \mathrm{~b}$ ), however, shows an onset potential close to $0.80 \mathrm{~V}_{\mathrm{Na}}$, which might represent the threshold for the detrimental surface reactions on the Sn electrode. Thus, to investigate this hypothesis, we ran this same half-cell configuration under a CCCV protocol during desodiation, where a constant voltage (CV) step was applied after the constant current step (CC). In the CV step, the cutoff voltage was fixed at $0.8 \mathrm{~V}_{\mathrm{Na}}$ and the $\mathrm{Sn}$ anode was left at this potential until the current dropped to $10 \%$ of the current of that was used for the CC step. As shown in Figure 3a, applying a CV step at $0.8 \mathrm{~V}_{\mathrm{Na}}$ results in a significant capacity decay upon cycling; a capacity loss of ca. $63 \%$ is observed after 50 cycles compared to only $13 \%$ without applying a CV step. These results highlight the effect of anodic reactions occurring at high cutoff voltages on the cycle life of Sn anodes.

Figure $3 \mathrm{~b}$ illustrates the percentage of the contributed capacity from the constant voltage steps $\left(\% Q_{\mathrm{CV}}\right)$ during desodiation, at $0.8 \mathrm{~V}$ Na, versus the number of cycles. The $\% Q_{\mathrm{CV}}$ can be calculated according to Equation 1

$$
\% Q_{\mathrm{CV}}=\frac{Q_{\mathrm{CV}}}{Q_{\mathrm{CC}}+Q_{\mathrm{CV}}} \times 100 \%
$$

where $Q_{\mathrm{CC}}$ and $Q_{\mathrm{CV}}$ are the contributed capacities from the constant current and constant voltage steps, respectively. During the first 4 cycles, the contributed capacity from the $\mathrm{CV}$ step is $\sim 0.8 \%$; however, starting from the $5^{\text {th }}$ cycle, the onset of capacity decay in Figure $3 \mathrm{a}$ the $\% Q_{\mathrm{CV}}$ increases rapidly, reaching a maximum of $5.2 \%$ at the $15^{\text {th }}$ cycle. Such a rise in $\% Q_{\mathrm{CV}}$ indicates an increasing difficulty to fully desodiate the $\mathrm{Sn}$ electrode, and is possibly the result of an associated increase in the electrode polarization, highlighting the cumulative effect of the anodic surface reactions that occur when the 
electrode is biased at $0.8 \mathrm{~V}_{\mathrm{Na}}$ during the $\mathrm{CV}$ step. Carbonate-based electrolytes undergo a catalyzed reductive decomposition on Sn surfaces during sodiation, ${ }^{45}$ but, desodiation of the $\mathrm{Sn}$ electrodes beyond $0.8 \mathrm{~V}_{\mathrm{Na}}$ might result in the formation of $\mathrm{Sn}^{\mathrm{Z}+}$ surface species that react with the electrolyte forming Sn-based intermediates that are easily decomposed during sodiation.

Figure 3c shows the relative irreversible capacity loss for the SEI formation (RICSEI) for all of the studied electrodes. The $\mathrm{RIC}_{\mathrm{SEI}}$ is calculated according to the difference between the sodiation capacity at cycle $n+1, Q_{n+1}^{\text {Sod }}$, and delivered desodiation capacity of the previous cycle, $Q_{n}^{\text {Desod }}$, relative to the desodiation capacity at the $n^{\text {th }}$ cycle according to Equation 2. ${ }^{39,46,47}$ Comparing the $\mathrm{RIC}_{\mathrm{SEI}}$ for the electrodes run at a cutoff voltage of 0.8 $\mathrm{V}_{\mathrm{Na}}$, with and without a CV step, illustrates a higher irreversible capacity loss for the formation of SEI when a CV step is applied, and thus, clearly illustrates the consequence of the anodic surface reaction occurring at the cutoff voltage on the electrolyte decomposition.

$$
\operatorname{RIC}_{\mathrm{SEI}}=\frac{Q_{n+1}^{\text {Sod }}-Q_{n}^{\text {Desod }}}{Q_{n}^{\text {Desod }}}
$$

In addition, we also calculated the relative irreversible capacity loss for the delivered capacity at the end of desodiation, RIC $_{\text {Desod, }}$ (Figure 3d), according to Equation 3. 39,46,47 The $\mathrm{RIC}_{\text {Desod }}$ simply represents the relative capacity decay per cycle and is an approximate measure of the accumulation of surface species that isolate the active materials either electronically or ionically, and/or the physical disconnection of the active materials. ${ }^{47}$ As shown in Figure 3c, all of the studied electrodes show an initial decrease in $\mathrm{RIC}_{\mathrm{SEI}}$, which is more noticeable for the electrode cycled up to a $1 \mathrm{~V}_{\mathrm{Na}}$ cutoff voltage. The reason for such an initial decrease in RICSEI is not clear; it is, however, always associated with a sudden increase in the $\mathrm{RIC}_{\text {Desod, }}$ as shown in Figure $3 \mathrm{~d}$. The observed increase in the $\mathrm{RIC}_{\text {Desod }}$ is not expected to be related to the formation of insulating layers

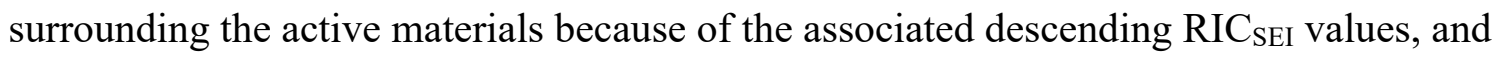
thus, might be due to disconnection or surface anodic reactions of the electrode materials at high cutoff voltages.

$$
\mathrm{RIC}_{\text {Desod }}=\frac{Q_{n}^{\text {Desod }}-Q_{n+1}^{\text {Desod }}}{Q_{n}^{\text {Desod }}}
$$


The morphologies of the $\mathrm{Sn}$ anodes before and after cycling at different cutoff voltages are shown in Figure 4. While the as-deposited electrode showed granular Sn particles, cycling for 50 cycles at 0.8 and $1 \mathrm{~V}_{\mathrm{Na}}$ results in coral-like structured films. The observed structure of these cycled films is consistent with the self-healing mechanism for $\mathrm{Sn}$ anodes in sodium-ion batteries that was recently proposed by Kim et al.; Sn pulverizes to nanometer-sized particles, which then coalesce to form a coral-like structure by room temperature sintering. ${ }^{48}$ Interestingly, the SEI layer is more clearly revealed on the surface for the $\mathrm{Sn}$ electrode cycled at $0.8 \mathrm{~V}_{\mathrm{Na}}$ with a $\mathrm{CV}$ step Figure $4 \mathrm{c}$ than that without a CV step Figure $4 b$, and is in agreement with the analysis shown in Figure $3 b$ and c.
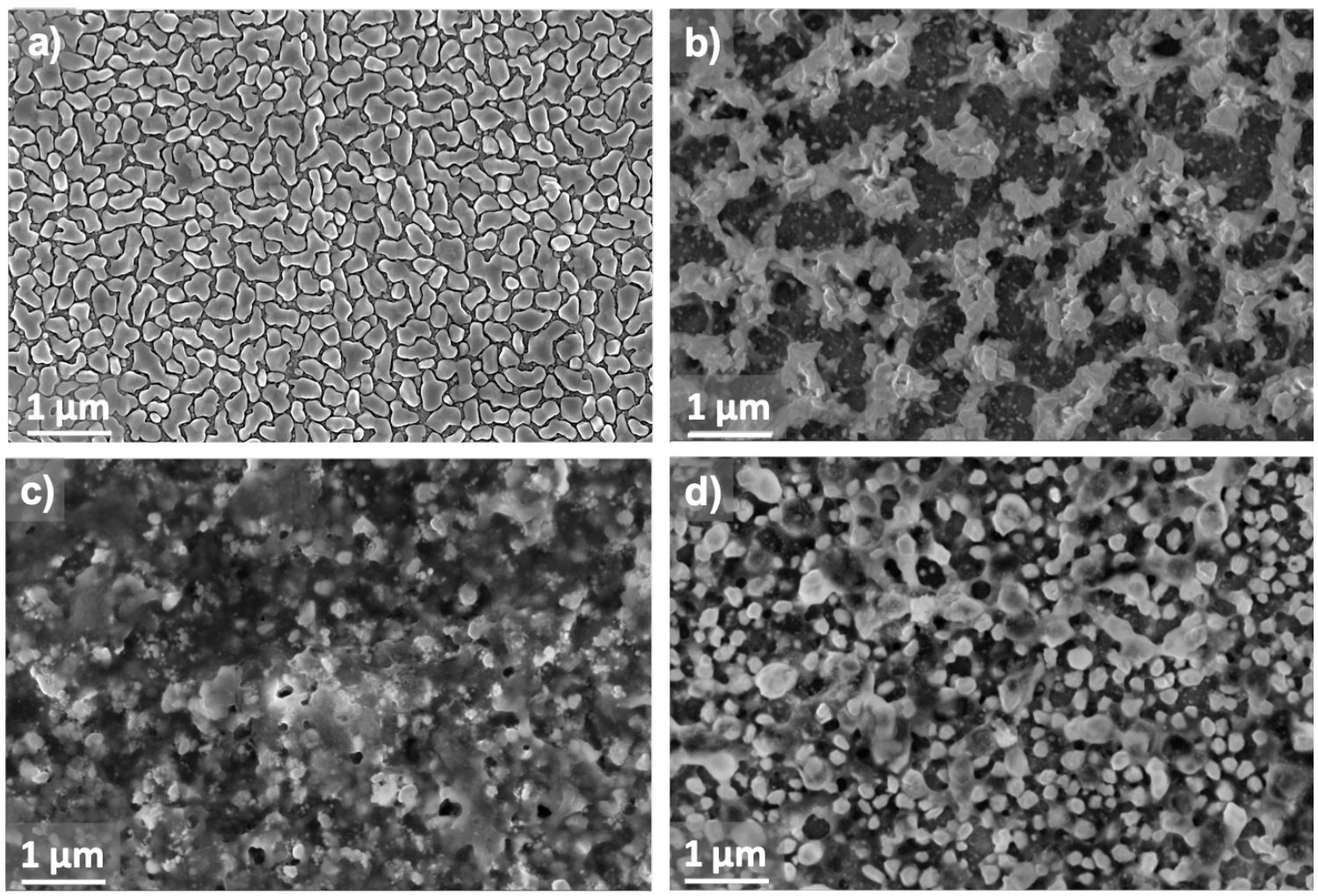

Figure 4. SEM images for elemental Sn film electrodes. (a) As-prepared, and after 50 cycles at desodiation cutoff voltages of $(b, c) 0.8 \mathrm{~V}$ Na and (d) $1 \mathrm{~V}_{\mathrm{Na}}$. (c) A constant voltage step at $0.8 \mathrm{~V} \mathrm{Na}$, with a current limit of $20 \mathrm{~mA} / \mathrm{g}$, is applied after the constant current step.

\section{Si and Sn binary anodes}

The capacity, capacity retention, and Coulombic efficiency as a function of cycle number for Si-Sn multilayers and co-sputtered films are shown in Figure 5. It should be noted that 
equal thicknesses (volumes) of $\mathrm{Si}$ and $\mathrm{Sn}$ correspond to the atomic ratio for the $\mathrm{Si}_{57} \mathrm{Sn}_{43}$ co-sputtered film. At this atomic ratio, the material consists of $76 \mathrm{wt} . \% \mathrm{Sn}$ and $24 \mathrm{wt} . \%$ $\mathrm{Si}$. The maximum contribution from $\mathrm{Sn}$ is therefore equal to $0.76 \times 847=645 \mathrm{mAh} / \mathrm{g}$. As can be seen in Figure 5a, the capacity of elemental Si is approximately $200 \mathrm{mAh} / \mathrm{g}_{\mathrm{Si}}$, which should contribute around $0.24 \times 200=48 \mathrm{mAh} / \mathrm{g}$ overall. The maximum capacity of the $10 \mathrm{~nm} \mathrm{Si} / 10 \mathrm{~nm} \mathrm{Sn}$ multilayer is $663 \mathrm{mAh} / \mathrm{g}$, which is close to what would be expected from a linear combination of the $\mathrm{Sn}$ and $\mathrm{Si}$. For the $3 \mathrm{~nm} \mathrm{Si} / 3 \mathrm{~nm} \mathrm{Sn}$ multilayer film, the maximum capacity is $645 \mathrm{mAh} / \mathrm{g}$, but the difference may be within experimental error of the deposition process. Whereas the $10 \mathrm{~nm} \mathrm{Si} / 10 \mathrm{~nm}$ Sn multilayer shows similar severe capacity degradation as the elemental Sn electrode, albeit more slowly, the capacity of the $3 \mathrm{~nm} \mathrm{Si} / 3 \mathrm{~nm}$ Sn multilayer electrode is very stable, showing capacity retention of $\sim 97 \%$ after 100 cycles (Figure $5 b$ ). 

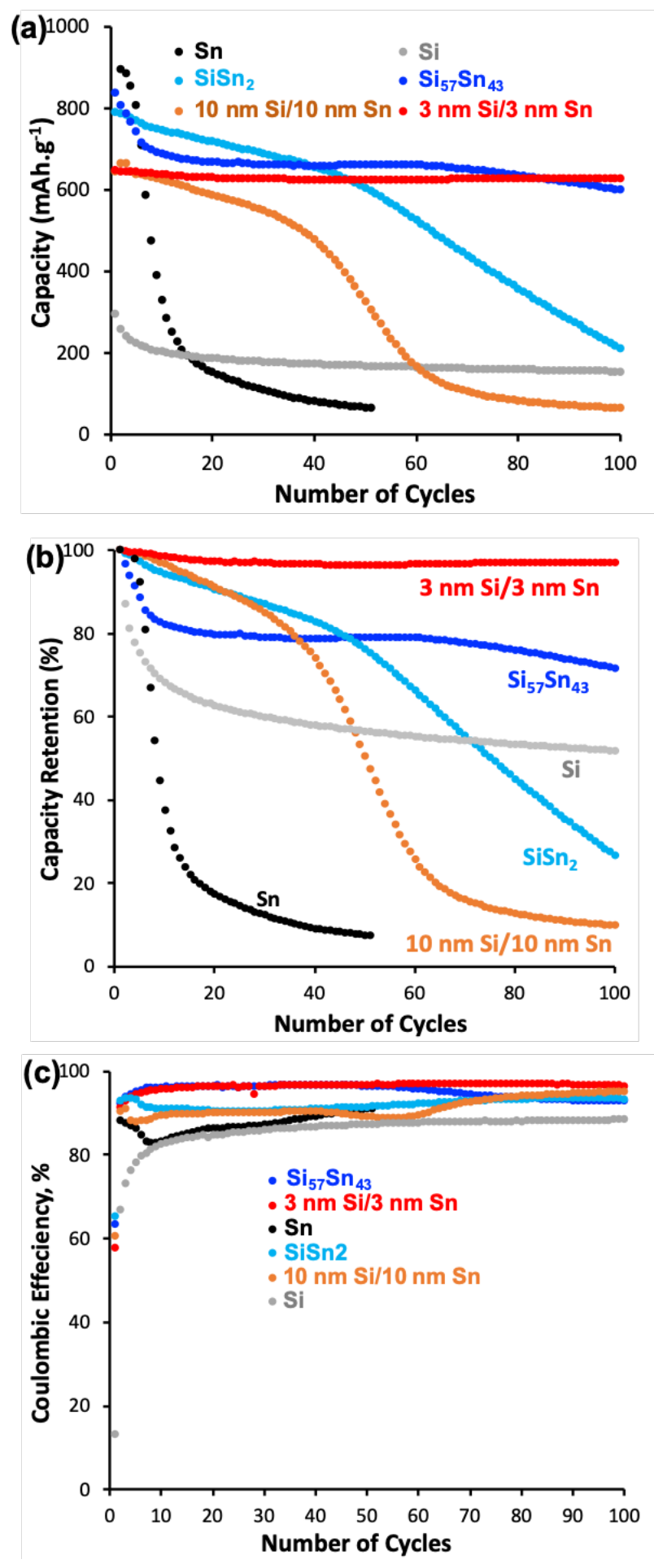

Figure 5. (a) Capacity, (b) capacity retention (c) and coulombic efficiency vs number of cycles for the different $\mathrm{Sn} / \mathrm{Si}$-based electrodes.

The co-sputtered films start at a reversible capacity that significantly exceeds that of both multilayers (10 $\mathrm{nm} \mathrm{Si} / 10 \mathrm{~nm} \mathrm{Sn}$, and $3 \mathrm{~nm} \mathrm{Si} / 3 \mathrm{~nm} \mathrm{Sn}$ ). $\mathrm{SiSn}_{2}$ is $\sim 90$ wt.\% Sn, and 
has a maximum capacity of $\sim 785 \mathrm{mAh} / \mathrm{g}$, which is very close to the nominal specific capacity based on a simple rule-of-mixtures $(0.1 \times 200+0.9 \times 847=782 \mathrm{mAh} / \mathrm{g})$. Physically, this rule-of-mixtures calculation represents the assumption that the microstructure of fully sodiated $\mathrm{SiSn}_{2}$ consists of a phase-separated mixture of a $\mathrm{Na}-\mathrm{Si}$ phase and a Na-Sn phase, each with capacities of 200 and $847 \mathrm{mAh} / \mathrm{g}$, respectively. The capacity then steadily decays to $\sim 700 \mathrm{mAh} / \mathrm{g}$ at cycle 40 , with the decay accelerating after cycles 45-50. The co-sputtered electrode with a composition equivalent to the multilayers, $\mathrm{Si}_{57} \mathrm{Sn}_{43}$, has a reversible capacity of $835 \mathrm{mAh} / \mathrm{g}$ after the first cycle. Given that the first capacity significantly exceeds the rule-of-mixtures capacity of $693 \mathrm{mAh} / \mathrm{g}$, this suggests that during the first few cycles, non-equilibrium phase(s) are being formed during sodiation, which could either be a novel ternary Si-Sn-Na phase and/or binary Si$\mathrm{Na}$ or $\mathrm{Sn}-\mathrm{Na}$ phase(s). However, after the first few cycles, the capacity rapidly decreases to $\sim 720 \mathrm{mAh} / \mathrm{g}$ by cycle 6 before stabilizing at $\sim 670 \mathrm{mAh} / \mathrm{g}$ after 15 cycles, which is very close to the value of $693 \mathrm{mAh} / \mathrm{g}$ expected for the phase-separated mixture. The claim of novel phase formation during the initial stages of sodiation is further supported by the distinctly different $d Q / d V$ curves (Figure 7d) during the first few cycles. During these initial cycles, there is a broad desodiation peak at $\sim 0.14 \mathrm{~V}$ that does not appear for phaseseparated mixtures of Si and Sn (Figure 7a-c).

It is worth noting that the sodiation of amorphous $\mathrm{Si}$ has a wide range of reported capacities, ${ }^{26,28,49}$ which are always much lower than the theoretical capacity of 954 $\mathrm{mAh} / \mathrm{g}$, which corresponds to the formation of a 1:1 ratio of sodium to silicon (NaSi). Thus, the mechanism of Na storage in a-Si is still not clear, but through detailed electrochemical characterization, Huang et al. reported a capacitive storage mechanism for the sodiation of a-Si and a reversible capacity of $240 \mathrm{mAh} / \mathrm{g}$, cycled at $200 \mathrm{~mA} / \mathrm{g} .{ }^{28}$ As shown in Figure S3, the sodiation profiles for a-Si appear to be essentially featureless. However, the $\mathrm{dQ} / \mathrm{dV}$ curves show that a broad desodiation peak exists at $\sim 300 \mathrm{mV} V_{\mathrm{Na}}$, indicating alloying of $\mathrm{Na}$ and Si probably during the sodiation constant voltage step at 1 $\mathrm{mV}_{\mathrm{Na}}$. 

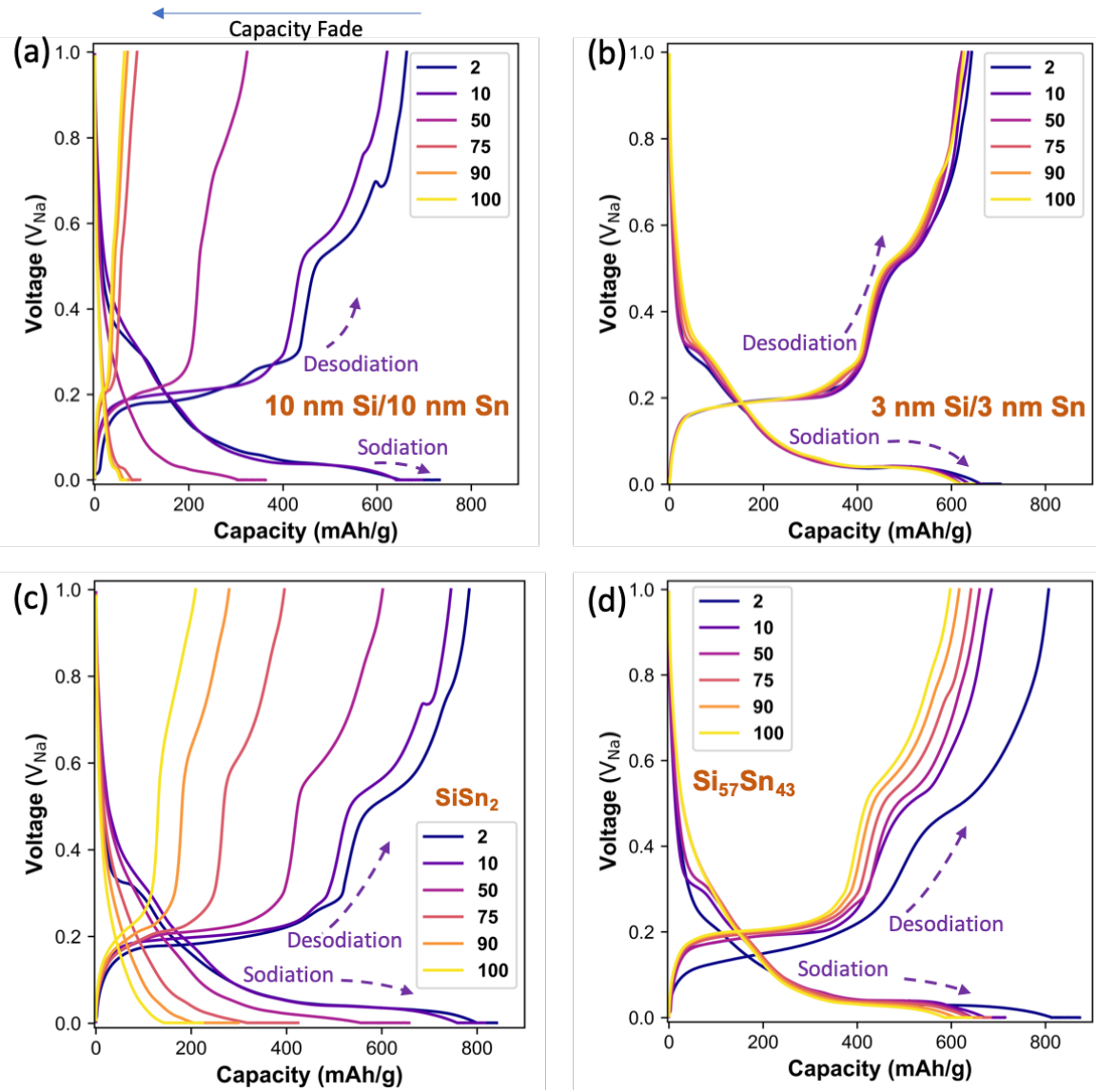

Figure 6. Voltage vs capacity (a-d) for $\mathrm{Si}$ and $\mathrm{Sn}$ multilayer films $(\mathrm{a}, \mathrm{b})$ and cosputtered (c, d) films cycled using a CCCV protocol with a CV step at $1 \mathbf{m V}_{\mathrm{Na}}$ for sodiation steps and a $C C$ protocol with a $1 \mathrm{~V}_{\mathrm{Na}}$ cutoff voltage for desodiation steps. The plateaus at the end of sodiation at $1 \mathrm{mV}_{\mathrm{Na}}$ in each panel represent the contributed capacity from the constant voltage steps. Cycle number is indicated in each corresponding figure legend.

For $10 \mathrm{~nm} \mathrm{Si} / 10 \mathrm{~nm} \mathrm{Sn}$, the voltage profiles (Figure 6a) superficially resemble those of the $50 \mathrm{~nm}$ Sn film (Figure 2a), with the widest plateau-like regions during desodiation at approximately $0.18,0.26,0.55$ and $0.65 \mathrm{~V}_{\mathrm{Na}}$, although the features in the corresponding dQ/dV curves are broadened considerably (Figure 7a). For $3 \mathrm{~nm} \mathrm{Si} / 3 \mathrm{~nm}$ Sn, all voltage plateaus (Figure 6b) have considerably higher slopes when compared to the $50 \mathrm{~nm}$ elemental Sn film, although the same 4 main features are recognizable as seen in the $\mathrm{dQ} / \mathrm{dV}$ profiles in Figure $7 \mathrm{~b}$. The voltage profiles and total capacity of the $3 \mathrm{~nm}$ $\mathrm{Si} / 3 \mathrm{~nm}$ Sn multilayer (Figure $6 \mathrm{~b}$ ) show very little evolution with cycling, indicating that the microstructure, or at least the degree of dispersion of the Si and Sn throughout the material, is highly stable. Co-sputtered $\mathrm{Si}_{57} \mathrm{Sn}_{43}$ consists of equal volumes of $\mathrm{Sn}$ and $\mathrm{Si}$ 
and the well known electrochemical response of $\mathrm{Sn}$ is no longer recognizable; only 2 sloping plateaus are observed initially, which become broad 'humps' in the corresponding $d Q / d V$ curves as seen in cycle 2 in Figure $7 d$. The $d Q / d V$ profiles quickly evolve to resemble those of the $3 \mathrm{~nm} \mathrm{Si} / 3 \mathrm{~nm}$ Sn multilayer and after only 5 cycles, they are nearly identical, as are their reversible capacities. $\mathrm{SiSn}_{2}$ has, however, 73 vol\% $\mathrm{Sn}$ based on the molar volumes of the elements, and its electrochemical response is, as a consequence, dominated by $\mathrm{Sn}$. $\mathrm{SiSn}_{2}$ has voltage and dQ/dV profiles strongly resembling those of the $50 \mathrm{~nm} \mathrm{Sn} \mathrm{film} \mathrm{(Figure} \mathrm{2b)} \mathrm{as} \mathrm{well} \mathrm{as} \mathrm{the} 10 \mathrm{~nm} \mathrm{Si} / 10 \mathrm{~nm} \mathrm{Sn}$ multilayer (Figure 7a) with noticeable capacity fade and decreasing peak intensities, respectively, throughout cycling. The $\mathrm{dQ} / \mathrm{dV}$ curves of the $3 \mathrm{~nm} \mathrm{Si} / 3 \mathrm{~nm} \mathrm{Sn}$ multilayer and co-sputtered $\mathrm{Si}_{57} \mathrm{Sn}_{43}$, show a small feature during sodiation at $\sim 70 \mathrm{mV}$ Na (Figure $7 \mathrm{~d}$ ) and a corresponding desodiation peak at $\sim 0.27 \mathrm{~V}_{\mathrm{Na}}$, that keeps growing with cycling for the multilayer, whereas the height of the peak begins to decrease at around cycle 50 for $\mathrm{Si}_{57} \mathrm{Sn}_{43}$. These features are also found in the dQ/dV curve for $50 \mathrm{~nm} \mathrm{Sn}$, (Figure 2b) and their emergence may signify Sn grain growth during cycling. 

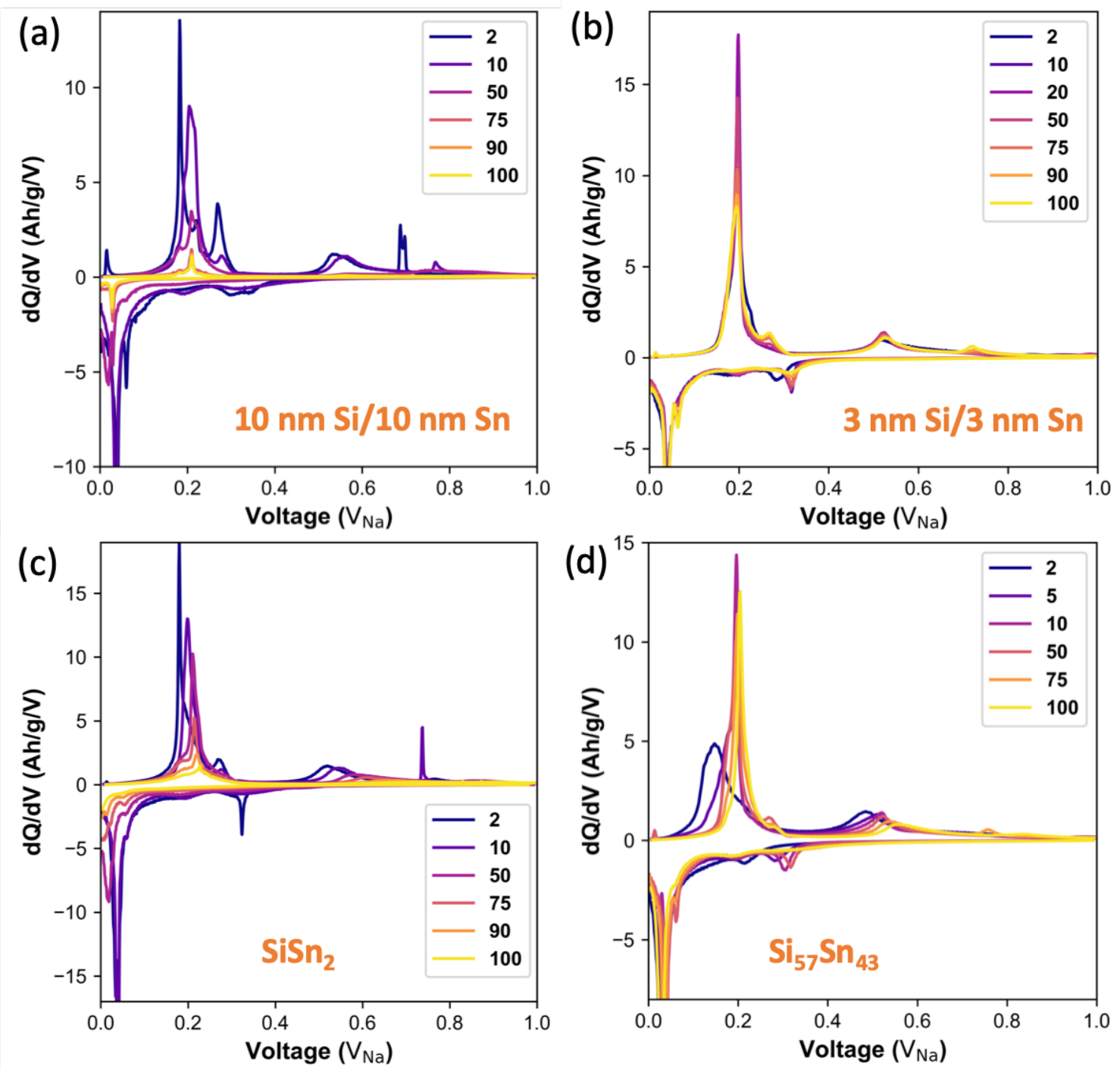

Figure 7. Differential capacity $v s$ voltage for Si and Sn multilayer (a, b) and cosputtered (c, d) films. Cycle number is indicated in each corresponding figure legend.

As shown in Figure 8, as-deposited $\mathrm{Si}_{57} \mathrm{Sn}_{43}$ is the only composition for which sputter deposition has resulted in a homogeneous and amorphous material and no crystalline phases are observed. The $\mathrm{Sn}(101)$ and (200) peaks in the $\mathrm{SiSn}_{2}$ film are not shifted with respect to the elemental Sn film. While germanium, another Group IV element, does show metastable solid solution behavior with $\mathrm{Sn}$, silicon does not. ${ }^{29,38}$ The $10 \mathrm{~nm} \mathrm{Si} / 10$ $\mathrm{nm} \mathrm{Sn}$ and $3 \mathrm{~nm} \mathrm{Si} / 3 \mathrm{~nm}$ Sn multilayers show clear evidence of crystalline $\mathrm{Sn}$ in their XRD patterns in the as-deposited state, although the peaks are much broader for $3 \mathrm{~nm}$ $\mathrm{Si} / 3 \mathrm{~nm} \mathrm{Sn}$, indicating a smaller grain size compared to $10 \mathrm{~nm} \mathrm{Si} / 10 \mathrm{~nm} \mathrm{Sn}$, but also 
compared to $\mathrm{SiSn}_{2}$. This observation is reflected in the SEM micrographs (Figure 9) of the as-deposited films where no grain structure is visible for the $\mathrm{Si}$ and $\mathrm{Si}_{57} \mathrm{Sn}_{43}$ films, very small grains can be discerned for $3 \mathrm{~nm} \mathrm{Si} / 3 \mathrm{~nm} \mathrm{Sn}$, and the largest grains are found in $10 \mathrm{~nm} \mathrm{Sn} / 10 \mathrm{~nm} \mathrm{Si}$ and $\mathrm{SiSn}_{2}$ films, consistent with the trend in the XRD peak widths. The integral breadth (IB) of the Sn (200) and (101) peaks for all compositions in the asdeposited and cycled states are summarized in Table S1.
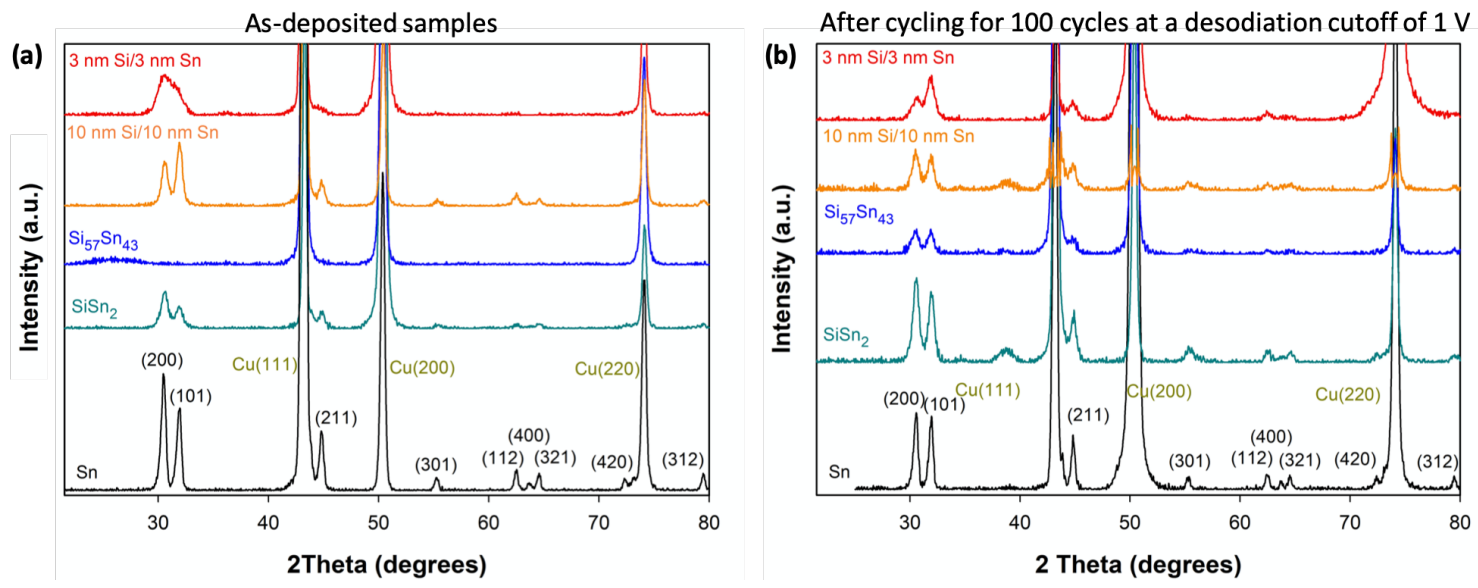

Figure 8. XRD patterns of (a) as-deposited films and (b) after 100 electrochemical cycles. Reference diffraction patterns: Sn (PDF no. 04-004-7747).

Compared to the as-deposited state, the peak widths of the cycled $10 \mathrm{~nm} \mathrm{Si} / 10 \mathrm{~nm} \mathrm{Sn}$ are essentially unchanged, although the signal-to-background ratio has clearly decreased for this film. The integral breadth (IB) of both peaks significantly decreased for $3 \mathrm{~nm}$ $\mathrm{Sn} / 3 \mathrm{~nm} \mathrm{Si}$ and $\mathrm{SiSn}_{2}$ after cycling for 100 cycles, indicating grain growth, which was also reflected in the evolution of the $\mathrm{dQ} / \mathrm{dV}$ curves as discussed in relation to Figure 7. After cycling, peaks of crystalline $\mathrm{Sn}$ are visible for $\mathrm{Si}_{57} \mathrm{Sn}_{43}$ as well, indicating phase separation of crystalline Sn. The XRD pattern of cycled $\mathrm{Si}_{57} \mathrm{Sn}_{43}$ was measured only after 100 cycles, but the evolution of the dQ/dV curves in cycle 1-5 (see Figure S4), combined with the rapid decline of the capacity to a value corresponding to a segregated mixture, strongly suggest that phase separation sets in immediately from cycle 1. Despite the strong similarity between the Si-Sn and Si-Sb binary phase diagrams, very low solid solubility, no compounds, a eutectic at a composition is almost $100 \% \mathrm{Sn}$ ( $\mathrm{Sb}$ ), and low solubility of $\mathrm{Si}$ in molten $\mathrm{Sn}$ and $\mathrm{Sb},{ }^{50}$ the behavior during sodiation cycling is very different between the two systems. Phase separation in Si-Sb was only apparent from the 
$\mathrm{dQ} / \mathrm{dV}$ curves and not at all from XRD except when the amount of Si was very low $(7 \%) .{ }^{51}$ For multilayer films, we found no evidence for intermixing in $\mathrm{Si} / \mathrm{Sn}$, contrary to $\mathrm{Si} / \mathrm{Sb} .^{51}$ The fact that the $\mathrm{dQ} / \mathrm{dV}$ curves for $\mathrm{Si}_{57} \mathrm{Sn}_{43}$ showed a very abrupt change to sharper, more 'bulk-like' features going from cycle 4 to cycle 5, indicates that if $\mathrm{Sn}$ crystallites remain below a certain size, the formation of crystalline $\mathrm{Na}-\mathrm{Sn}$ phases is suppressed. Since $3 \mathrm{~nm} \mathrm{Si} / 3 \mathrm{~nm}$ Sn did show sharp dQ/dV features, our results suggest that this transition happens around or below $3 \mathrm{~nm}$, and a more precise determination of this limit would be an interesting area for further study. 

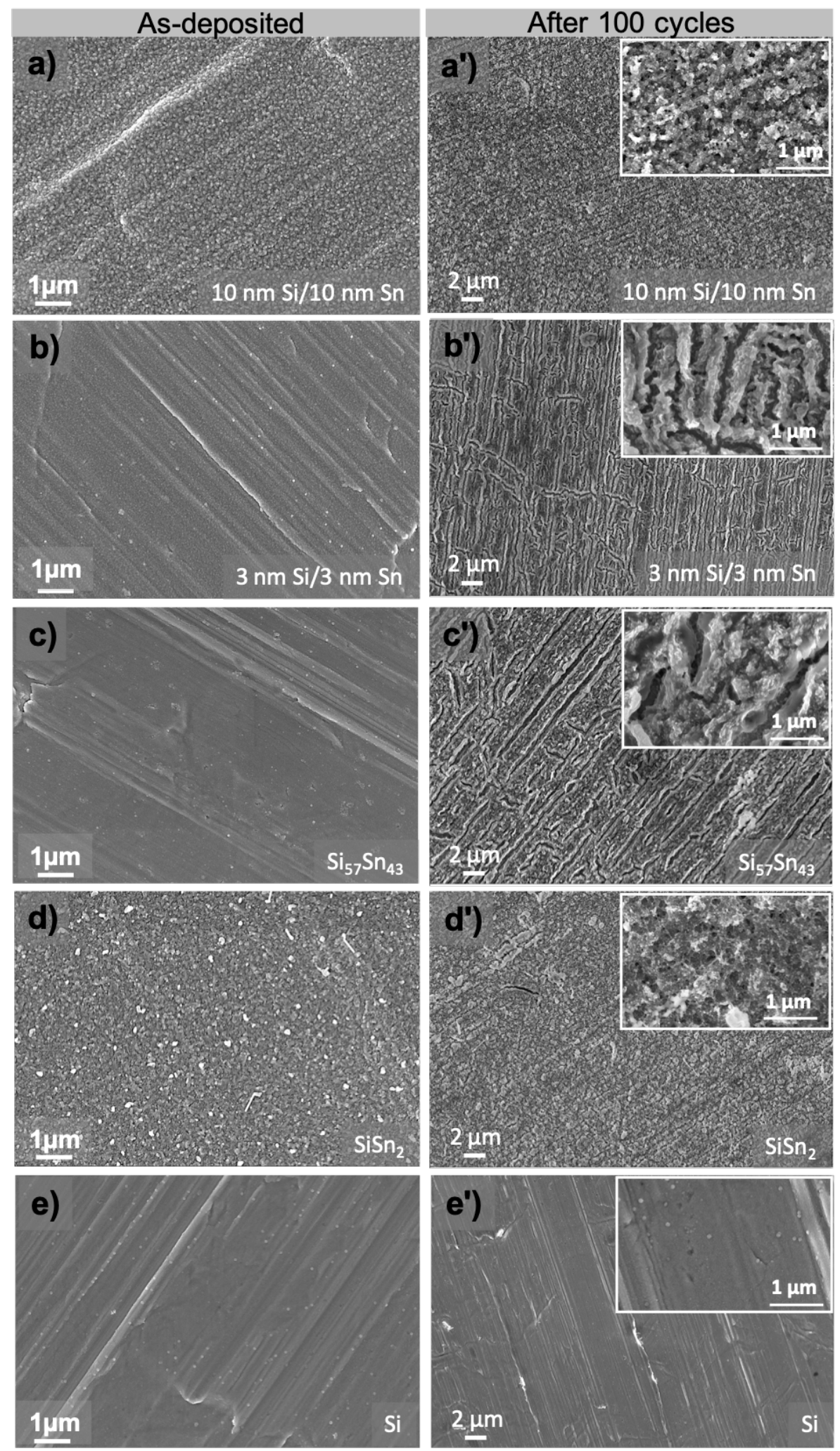

Figure 9. SEM images for the different $\mathrm{Sn} / \mathrm{Si}$-based electrodes before and after cycling for 100 cycles at a $1 \mathrm{~V}_{\mathrm{Na}}$ desodiation cutoff voltage. 
Despite the fact that the surface areas of the cycled electrodes (Figure 9) appear to be much higher for the Sn-Si films as compared to the $50 \mathrm{~nm} \mathrm{Sn}$, the Coulombic efficiency (Figure 5c) is higher for $3 \mathrm{~nm} \mathrm{Si} / 3 \mathrm{~nm} \mathrm{Sn}$ and $\mathrm{Si}_{57} \mathrm{Sn}_{43}$, even when compared to $50 \mathrm{~nm} \mathrm{Sn}$ with a $0.8 \mathrm{~V}_{\mathrm{Na}}$ cut-off (Figure $3 \mathrm{a}$ ). The observed Coulombic efficiency is a clear indication that in addition to refining the microstructure and improving the cycling stability, Si addition to Sn also profoundly changes the reactivity with the electrolyte, which is all the more surprising since the Coulombic efficiency of elemental Si is so consistently low, $<85 \%$, indicating that a stable SEI is not formed on a Si surface. Similar 'synergetic' effects have been observed on Si-Sn LIB anodes as well, resulting in both improved capacity retention as well as improved Coulombic efficiency. ${ }^{36,52}$ Finally, Si addition appears to eliminate the passivation mechanism that occurred on pure Sn when cycled up to $1 \mathrm{~V}_{\mathrm{Na}}$, enabling stable cycling under these 'harsher' conditions.

\section{CONCLUSIONS}

A family of films comprising tin and silicon was prepared with both multilayer architectures and atomically mixed compositions (co-sputtered) and then tested as anodes in sodium-ion batteries. The mixed tin-silicon films showed improved capacity retention and higher Coulombic efficiencies for up to 100 cycles, compared to elemental $\mathrm{Sn}$ and $\mathrm{Si}$ anodes. The multilayer anodes were the most stable as confinement of the tin, in particular, was found to result in two key points: (i) stabilization of its nanostructure, and (ii) alteration of the surface chemistry resulting in less formation of SEI. The Si interlayers appear to act as protective layers that minimize the direct contact of Sn particles with the electrolyte and reduce pulverization upon cycling.

\section{ASSOCIATED CONTENT}

\section{Supporting Information}

XRD, Capacity retention and coulombic efficiency of Sn electrodes, voltage profiles, and differential capacity plots of Sn and Si films, table of XRD integral breadth of asdeposited and cycled films and differential capacity plot of co-sputtered $\mathrm{Si}_{57} \mathrm{Sn}_{43}$. 


\section{AUTHOR INFORMATION}

\section{Corresponding Authors}

Jillian M. Buriak - Department of Chemistry, University of Alberta, Edmonton, AB

T6G 2G2, Canada; National Research Council Canada, Nanotechnology Research

Centre, Edmonton, AB T6G 2M9, Canada; ORCID: 0000-0002-9567-4328;

Email: jburiak@ualberta.ca

Sayed Youssef Sayed - Department of Chemistry, University of Alberta, Edmonton, AB T6G 2G2, Canada; National Research Council Canada, Nanotechnology Research Centre, Edmonton, AB T6G 2M9, Canada; ORCID: 0000-0003-1575-676X;

Email: synagy@ualberta.ca

W. Peter Kalisvaart - Department of Chemistry, University of Alberta, Edmonton, AB T6G 2G2, Canada; National Research Council Canada, Nanotechnology Research Centre, Edmonton, AB T6G 2M9, Canada; ORCID: 0000-0003-1228-906X;

Email: pkalisva@ualberta.ca

\section{Authors}

Erik J. Luber - Department of Chemistry, University of Alberta, Edmonton, AB T6G 2G2, Canada; National Research Council Canada, Nanotechnology Research Centre, Edmonton, AB T6G 2M9, Canada; ORCID: 0000-0003-1623-0102;

Brian C. Olsen - Department of Chemistry, University of Alberta, Edmonton, AB T6G 2G2, Canada; National Research Council Canada, Nanotechnology Research Centre, Edmonton, AB T6G 2M9, Canada; ORCID: 0000-0001-9758-3641;

\section{Notes}

The authors declare no competing financial interest. 


\section{ACKNOWLEDGMENTS}

This work was supported by Future Energy Systems of the University of Alberta (https://futureenergysystems.ca; grant numbers T12-P04 and T12-P01), the Natural

Sciences and Engineering Research Council (NSERC, grant number RGPIN-2014-05195 and RGPIN-2018-04294), Alberta Innovates Technology Futures (grant numbers AITF iCORE IC50-T1 G2013000198 and CTDP-G2018000919), and the Canada Research Chairs program (CRC 207142). The authors would like to thank Dr. Hezhen Xie for valuable discussions and help. The authors would like to thank Dr. Michael D. Fleischauer for the use of lab facilities at the Nanotechnology Research Centre in Edmonton.

\section{REFERENCES}

(1) Gür, T. M. Review of Electrical Energy Storage Technologies, Materials and Systems: Challenges and Prospects for Large-Scale Grid Storage. Energy Environ. Sci. 2018, 11, 2696-2767.

(2) Larcher, D.; Tarascon, J.-M. Towards Greener and More Sustainable Batteries for Electrical Energy Storage. Nat. Chem. 2015, 7, 19-29.

(3) Goodenough, J. B.; Park, K.-S. The Li-Ion Rechargeable Battery: A Perspective. $J$. Am. Chem. Soc. 2013, 135, 1167-1176.

(4) Berg, E. J.; Villevieille, C.; Streich, D.; Trabesinger, S.; Novák, P. Rechargeable Batteries: Grasping for the Limits of Chemistry. J. Electrochem. Soc. 2015, 162, A2468A2475.

(5) Vaalma, C.; Buchholz, D.; Weil, M.; Passerini, S. A Cost and Resource Analysis of Sodium-Ion Batteries. Nat. Rev. Mater. 2018, 3, 18013.

(6) Schmuch, R.; Wagner, R.; Hörpel, G.; Placke, T.; Winter, M. Performance and Cost of Materials for Lithium-Based Rechargeable Automotive Batteries. Nat. Energy 2018, 3, $267-278$. 
(7) Kwak, W.-J.; Rosy; Sharon, D.; Xia, C.; Kim, H.; Johnson, L. R.; Bruce, P. G.; Nazar, L. F.; Sun, Y.-K.; Frimer, A. A.; et al. Lithium-Oxygen Batteries and Related Systems: Potential, Status, and Future. Chem. Rev. 2020, [ASAP]. DOI:

10.1021/acs.chemrev.9b00609. Published Online: March 5, 2020.

(8) Grey, C. P.; Tarascon, J. M. Sustainability and in Situ Monitoring in Battery Development. Nat. Mater. 2017, 16, 45-56.

(9) Kubota, K.; Dahbi, M.; Hosaka, T.; Kumakura, S.; Komaba, S. Towards K-Ion and Na-Ion Batteries as "Beyond Li-Ion". Chem. Rec. 2018, 18, 459-479.

(10) Yan, G.; Mariyappan, S.; Rousse, G.; Jacquet, Q.; Deschamps, M.; David, R.; Mirvaux, B.; Freeland, J. W.; Tarascon, J.-M. Higher Energy and Safer Sodium Ion Batteries via an Electrochemically Made Disordered $\mathrm{Na}_{3} \mathrm{~V}_{2}\left(\mathrm{PO}_{4}\right)_{2} \mathrm{~F}_{3}$ Material. Nat. Commun. 2019, 10, 585.

(11) Kubota, K.; Komaba, S. Review_-Practical Issues and Future Perspective for Na-Ion Batteries. J. Electrochem. Soc. 2015, 162, A2538.

(12) Wang, L.; Song, J.; Qiao, R.; Wray, L. A.; Hossain, M. A.; Chuang, Y.-D.; Yang, W.; Lu, Y.; Evans, D.; Lee, J.-J.; et al. Rhombohedral Prussian White as Cathode for Rechargeable Sodium-Ion Batteries. J. Am. Chem. Soc. 2015, 137, 2548-2554.

(13) Wan, F.; Wu, X.-L.; Guo, J.-Z.; Li, J.-Y.; Zhang, J.-P.; Niu, L.; Wang, R.-S. Nanoeffects Promote the Electrochemical Properties of Organic $\mathrm{Na}_{2} \mathrm{C}_{8} \mathrm{H}_{4} \mathrm{O}_{4}$ as Anode Material for Sodium-Ion Batteries. Nano Energy 2015, 13, 450-457.

(14) Okamoto, Y. Density Functional Theory Calculations of Alkali Metal (Li, Na, and K) Graphite Intercalation Compounds. J. Phys. Chem. C 2014, 118, 16-19.

(15) Stevens, D. A.; Dahn, J. R. High Capacity Anode Materials for Rechargeable Sodium-Ion Batteries. J. Electrochem. Soc. 2000, 147, 1271-1273.

(16) Stevens, D. A.; Dahn, J. R. The Mechanisms of Lithium and Sodium Insertion in Carbon Materials. J. Electrochem. Soc. 2001, 148, A803-A811. 
(17) Bommier, C.; Surta, T. W.; Dolgos, M.; Ji, X. New Mechanistic Insights on Na-Ion Storage in Nongraphitizable Carbon. Nano Lett. 2015, 15, 5888-5892.

(18) Komaba, S.; Matsuura, Y.; Ishikawa, T.; Yabuuchi, N.; Murata, W.; Kuze, S. Redox Reaction of Sn-Polyacrylate Electrodes in Aprotic Na Cell. Electrochem. Commun. 2012, $21,65-68$.

(19) Lotfabad, E. M.; Ding, J.; Cui, K.; Kohandehghan, A.; Kalisvaart, W. P.; Hazelton, M.; Mitlin, D. High-Density Sodium and Lithium Ion Battery Anodes from Banana Peels. ACS Nano 2014, 8, 7115-7129.

(20) Darwiche, A.; Dugas, R.; Fraisse, B.; Monconduit, L. Reinstating Lead for HighLoaded Efficient Negative Electrode for Rechargeable Sodium-Ion Battery. J. Power Sources 2016, 304, 1-8.

(21) Kim, H.; Kim, H.; Ding, Z.; Lee, M. H.; Lim, K.; Yoon, G.; Kang, K. Recent Progress in Electrode Materials for Sodium-Ion Batteries. Adv. Energy Mater. 2016, 6, 1600943.

(22) Zhang, B.; Rousse, G.; Foix, D.; Dugas, R.; Corte, D. A. D.; Tarascon, J.-M. Microsized Sn as Advanced Anodes in Glyme-Based Electrolyte for Na-Ion Batteries. Adv. Mater. 2016, 28, 9824-9830.

(23) Tan, H.; Chen, D.; Rui, X.; Yu, Y. Peering into Alloy Anodes for Sodium-Ion Batteries: Current Trends, Challenges, and Opportunities. Adv. Funct. Mater. 2019, 29, 1808745.

(24) Legrain, F.; Malyi, O. I.; Manzhos, S. Comparative Computational Study of the Energetics of Li, Na, and Mg Storage in Amorphous and Crystalline Silicon. Comput. Mater. Sci. 2014, 94, 214-217.

(25) Jung, S. C.; Jung, D. S.; Choi, J. W.; Han, Y.-K. Atom-Level Understanding of the Sodiation Process in Silicon Anode Material. J. Phys. Chem. Lett. 2014, 5, 1283-1288.

(26) Xu, Y.; Swaans, E.; Basak, S.; Zandbergen, H. W.; Borsa, D. M.; Mulder, F. M. Reversible Na-Ion Uptake in Si Nanoparticles. Adv. Energy Mater. 2016, 6, 1501436. 
(27) Jangid, M. K.; Vemulapally, A.; Sonia, F. J.; Aslam, M.; Mukhopadhyay, A.

Feasibility of Reversible Electrochemical Na-Storage and Cyclic Stability of Amorphous Silicon and Silicon-Graphene Film Electrodes. J. Electrochem. Soc. 2017, 164, A2559A2565.

(28) Huang, S.; Liu, L.; Zheng, Y.; Wang, Y.; Kong, D.; Zhang, Y.; Shi, Y.; Zhang, L.; Schmidt, O. G.; Yang, H. Y. Efficient Sodium Storage in Rolled-up Amorphous Si Nanomembranes. Adv. Mater. 2018, 30, 1706637.

(29) Abel, P. R.; Fields, M. G.; Heller, A.; Mullins, C. B. Tin-Germanium Alloys as Anode Materials for Sodium-Ion Batteries. ACS Appl. Mater. Interfaces 2014, 6, 1586015867.

(30) Xie, H.; Tan, X.; Luber, E. J.; Olsen, B. C.; Kalisvaart, W. P.; Jungjohann, K. L.; Mitlin, D.; Buriak, J. M. $\beta$-SnSb for Sodium Ion Battery Anodes: Phase Transformations Responsible for Enhanced Cycling Stability Revealed by in Situ TEM. ACS Energy Lett. 2018, 3, 1670-1676.

(31) Nam, D.-H.; Kim, T.-H.; Hong, K.-S.; Kwon, H.-S. Template-Free Electrochemical Synthesis of Sn Nanofibers as High-Performance Anode Materials for Na-Ion Batteries. ACS Nano 2014, 8, 11824-11835.

(32) Huang, J.; Guo, X.; Du, X.; Lin, X.; Huang, J.-Q.; Tan, H.; Zhu, Y.; Zhang, B. Nanostructures of Solid Electrolyte Interphases and Their Consequences for Microsized Sn Anodes in Sodium Ion Batteries. Energy Environ. Sci. 2019, 12, 1550-1557.

(33) Cheng, Y.; Huang, J.; Li, R.; Xu, Z.; Cao, L.; Ouyang, H.; Li, J.; Qi, H.; Wang, C. Enhanced Cycling Performances of Hollow Sn Compared to Solid Sn in Na-Ion Battery. Electrochim. Acta 2015, 180, 227-233.

(34) Kalisvaart, W. P.; Xie, H.; Olsen, B. C.; Luber, E. J.; Buriak, J. M. Understanding the Mechanism of Enhanced Cycling Stability in Sn-Sb Composite Na-Ion Battery Anodes: Operando Alloying and Diffusion Barriers. ACS Appl. Energy Mater. 2019, 2, 5133-5139. 
(35) Li, Z.; Ding, J.; Mitlin, D. Tin and Tin Compounds for Sodium Ion Battery Anodes: Phase Transformations and Performance. Acc. Chem. Res. 2015, 48, 1657-1665.

(36) Obrovac, M. N.; Chevrier, V. L. Alloy Negative Electrodes for Li-Ion Batteries. Chem. Rev. 2014, 114, 11444-11502.

(37) Witte, J.; Schnering, H. G.; Klemm, W. Das Verhalten der Alkalimetalle zu Halbmetallen. XI. Die Kristallstruktur von NaSi und NaGe. Z. anorg. allg. Chem. 1964, $327,260-273$.

(38) Farbod, B.; Cui, K.; Kalisvaart, W. P.; Kupsta, M.; Zahiri, B.; Kohandehghan, A.; Lotfabad, E. M.; Li, Z.; Luber, E. J.; Mitlin, D. Anodes for Sodium Ion Batteries Based on Tin-Germanium-Antimony Alloys. ACS Nano 2014, 8, 4415-4429.

(39) Sayed, S. Y.; Kalisvaart, W. P.; Olsen, B. C.; Luber, E. J.; Xie, H.; Buriak, J. M. Alternating Silicon and Carbon Multilayer-Structured Anodes Suppress Formation of the c-Li3.75Si Phase. Chem. Mater. 2019, 31, 6578-6589.

(40) Ellis, L. D.; Ferguson, P. P.; Obrovac, M. N. Sodium Insertion into Tin Cobalt Carbon Active/Inactive Nanocomposite. J. Electrochem. Soc. 2013, 160, A869.

(41) Chevrier, V. L.; Ceder, G. Challenges for Na-Ion Negative Electrodes. J. Electrochem. Soc. 2011, 158, A1011.

(42) Ellis, L. D.; Hatchard, T. D.; Obrovac, M. N. Reversible Insertion of Sodium in Tin. J. Electrochem. Soc. 2012, 159, A1801-A1805.

(43) Baggetto, L.; Ganesh, P.; Meisner, R. P.; Unocic, R. R.; Jumas, J.-C.; Bridges, C. A.; Veith, G. M. Characterization of Sodium Ion Electrochemical Reaction with Tin Anodes: Experiment and Theory. J. Power Sources 2013, 234, 48-59.

(44) Li, T.; Gulzar, U.; Proietti Zaccaria, R.; Capiglia, C.; Hackney, S. A.; Aifantis, K. E. Damage Formation in Sn Film Anodes of Na-Ion Batteries. J. Phys. Chem. C 2019, 123, $15244-15250$. 
(45) Bridel, J.-S.; Grugeon, S.; Laruelle, S.; Hassoun, J.; Reale, P.; Scrosati, B.;

Tarascon, J.-M. Decomposition of Ethylene Carbonate on Electrodeposited Metal Thin Film Anode. J. Power Sources 2010, 195, 2036-2043.

(46) Xie, H.; Sayed, S. Y.; Kalisvaart, W. P.; Schaper, S. J.; Müller-Buschbaum, P.; Luber, E. J.; Olsen, B. C.; Haese, M.; Buriak, J. M. Adhesion and Surface Layers on Silicon Anodes Suppress Formation of c- $\mathrm{Li}_{3.75} \mathrm{Si}$ and Solid-Electrolyte Interphase. $A C S$ Appl. Energy Mater. 2020, 3, 1609-1616.

(47) Gauthier, M.; Mazouzi, D.; Reyter, D.; Lestriez, B.; Moreau, P.; Guyomard, D.; Roué, L. A Low-Cost and High Performance Ball-Milled Si-Based Negative Electrode for High-Energy Li-Ion Batteries. Energy Environ. Sci. 2013, 6, 2145-2155.

(48) Kim, C.; Kim, I.; Kim, H.; Sadan, M. K.; Yeo, H.; Cho, G.; Ahn, J.; Ahn, J.; Ahn, H. A Self-Healing Sn Anode with an Ultra-Long Cycle Life for Sodium-Ion Batteries. $J$. Mater. Chem. A 2018, 6, 22809-22818.

(49) Qiu, D.-F.; Ma, X.; Zhang, J.-D.; Lin, Z.-X.; Zhao, B. Mesoporous Silicon Microspheres Produced from in Situ Magnesiothermic Reduction of Silicon Oxide for High-Performance Anode Material in Sodium-Ion Batteries. Nanoscale Res. Lett. 2018, 13,275 .

(50) Okamoto, H. Desk Handbook: Phase Diagrams for Binary Alloys; ASM International, 2000.

(51) Kalisvaart, W. P.; Olsen, B. C.; Luber, E. J.; Buriak, J. M. Sb-Si Alloys and Multilayers for Sodium Ion Battery Anodes. ACS Appl. Mater. Interfaces 2019, 2, 22052213.

(52) Hatchard, T. D.; Dahn, J. R. Study of the Electrochemical Performance of Sputtered $\mathrm{Si}_{1-\mathrm{x}} \mathrm{Sn}_{\mathrm{x}}$ Films. J. Electrochem. Soc. 2004, 151, A1628-A1635. 